\title{
Ensino Médio: trajetória histórica e a dualidade educacional presente nas diferentes reformas
}

\author{
Christiani Bortoloto Lopes* \\ Claudimara Cassoli Bortoloto** \\ Shiderlene Vieira de Almeida***
}

\section{Resumo}

O artigo apresenta um estudo bibliográfico sobre a dualidade educacional do Ensino Médio e sua manifestação histórica nas diferentes reformas que atingiram essa etapa de ensino. Destaca-se que a dualidade se configura na existência de um sistema dual de educação, que visa a atender os interesses das diferentes classes existentes no interior da sociedade. Para isso, recuperaram-se as diversas reformas, desde os anos 1940 até meados dos anos 2000, e estabeleceu-se um diálogo com um conjunto de autores, revelando os limites das mesmas e sua vinculação com as demandas do setor produtivo. Além disso, foram destacadas as características peculiares das reformas dos anos 1990, consubstanciadas na Lei n 9.394/1996, a Lei de Diretrizes e Bases, que colocou o Ensino Médio como etapa final da educação básica, ao passo que deu bases legais para a promulgação de novas legislações que intensificaram a dualidade educacional, como o Decreto $n^{\circ}$ 2.208/1997, o Decreto ${ }^{\circ}$ 5.154/2004 e a Lei ${ }^{\circ}$ 12.513/2011, que instituiu o Pronatec. As disputas de diferentes interesses sobre a educação levaram o Estado a promulgar o Decreto no 5.154/2004 e revogar o Decreto $n^{\circ}$ 2.208/1997, revertendo o papel do Estado quanto à oferta de educação profissional integrada ao nível médio. A simples retomada do Estado para com essas políticas não significou a extinção da dualidade educacional, haja vista que essa carece de constante luta imposta pelos trabalhadores no interior do Estado, sobretudo no âmbito das políticas educacionais, bem como demanda a própria superação desse modelo de sociedade, pautado na diferença de classes.

Palavras-chave: Ensino Médio. Políticas Públicas em Educação. Reformas de Ensino.

\footnotetext{
* Mestra em Educação pela Universidade Estadual do Oeste do Paraná (UNIOESTE). Assistente Social da Prefeitura Municipal de Cascavel, Paraná.

*** Mestra em Educação pela Universidade Estadual do Oeste do Paraná (UNIOESTE). Professora da Universidade Tecnológica Federal do Paraná (UTFPR), Campus de Medianeira.

*** Doutora em Educação pela Universidade Estadual de Campinas (UNICAMP). Professora da Universidade Tecnológica Federal do Paraná (UTFPR), Campus de Medianeira.
} 


\section{Introdução}

Este artigo apresenta uma discussão sobre a dualidade educacional do Ensino Médio, de forma a demonstrar como ela se reproduz no conjunto das reformas dessa etapa de ensino, inauguradas desde os anos 1940 até meados dos anos 2000. A discussão permeia as suas principais características marcadas por um sistema paralelo de educação profissional, reservando aos trabalhadores uma formação técnica e reduzida a sua preparação enquanto vendedores da força de trabalho.

Posteriormente, é abordada a questão da educação no contexto da Ditadura Militar, período em que o tecnicismo ganhou força e demandou uma formação vinculada às demandas do setor produtivo,

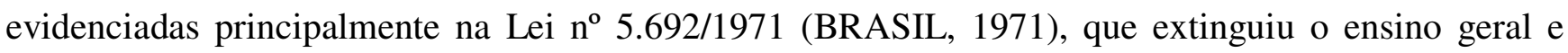
tornou compulsória a educação profissionalizante, revogada, posteriormente, pela Lei $n^{\circ}$ 7.044/1982 (BRASIL, 1982).

O contexto da Ditadura Militar levou à mobilização popular contra esse regime, o que não se limitava ao combate à forma de governo, mas era uma luta também pela democracia. Questões como a ampliação e qualidade do sistema público educacional perpassavam as reivindicações populares. Sendo assim, aponta-se a importância de movimentos progressistas de educadores que impuseram perante o Estado as demandas educacionais, configuradas, sobretudo, no Ensino Médio, assim como a necessidade da garantia de uma educação baseada na formação integral do sujeito.

Nesse contexto de lutas e disputas pelos rumos da educação de Ensino Médio no país, é delineado o percurso anterior à aprovação da Lei n 9.394/1996, Lei de Diretrizes e Bases da Educação (LDB) (BRASIL, 1996). O aspecto minimalista dessa lei foi consubstanciado nas mudanças do Substitutivo Jorge Hage, que retirou um conjunto de direitos e condições que viabilizariam a formação politécnica e domínio do trabalhador sobre os fundamentos do trabalho.

Os anos 1990 indicaram profundas reforma, por isso se resgata a discussão sobre a LDB, que colocou o Ensino Médio como parte final da educação básica; e, ao mesmo tempo, deu legitimidade para a aprovação do Decreto no 2.208/1997 (BRASIL, 1997), do Decreto $n^{\circ}$ 5.154/2004 (BRASIL, 2004) e, por fim, da Lei no 12.513/2011 (BRASIL, 2011), que instituiu o Programa Nacional de Acesso ao Ensino Técnico e Emprego (Pronatec). Sendo assim, objetiva-se demarcar as características peculiares de cada reforma, a presença da dualidade educacional, os limites para o seu rompimento na sociedade capitalista, bem como a hegemonia do setor produtivo sobre elas. 


\section{A dualidade educacional no conjunto das reformas do Ensino Médio: das Leis Orgânicas ao Pronatec}

O ensino médio configura-se como a etapa final da Educação Básica. Situada entre o Ensino Fundamental e a Educação Superior, constitui o ponto nevrálgico da dualidade existente no sistema educacional brasileiro. Desse modo, este artigo pretende discutir as principais reformas que incidiram sobre sua organização, pautadas em diferentes demandas da sociedade, na sua submissão aos interesses produtivos e na reprodução da dualidade educacional.

A literatura que trata da dualidade educacional, embasada em autores como Frigotto, Ciavatta e Ramos (2011), Xavier (1990), Kuenzer (2005), Cunha (2000) e Cêa (2006), compartilha o entendimento de que essa dualidade tem sua maior expressão no Ensino Médio. Isso porque esse nível educacional cumpre a função de preparar a classe dominante para continuar a reproduzir as relações de domínio e poder, ao passo que é oferecida de forma fragmentada para a classe trabalhadora, a fim de prepará-la para o trabalho. Legitima-se, assim, a formação intelectual e humanista para aqueles que conduzem os rumos da nação, e a educação profissional e específica aos que impulsionam a industrialização.

A incapacidade de superar a contradição entre formação geral versus formação profissional, dentro desse contexto de preocupações, acabou garantindo a pior espécie de especialização no campo do ensino, a separação entre a educação das camadas privilegiadas e a educação das camadas subalternas. (XAVIER, 1990, p. 114).

O processo de desenvolvimento do sistema capitalista no Brasil possui características próprias no cenário mundial, por se tratar de um país que apresenta peculiaridades do capitalismo periférico. É nesse cenário que se pretende analisar o Ensino Médio, etapa do ensino que intermedeia a continuidade dos estudos e a formação para o trabalho. A desigual oferta educacional entre as diferentes classes sociais marca o dualismo educacional, estando relacionada ao antagonismo de classes que perpassa a sociedade brasileira.

Conforme Xavier (1990), a elite brasileira sempre teve a exclusividade e o acesso à escola, como forma de legitimar sua dominação de classe. Por séculos de colonização, o trabalhador desempenhou seu trabalho sem a necessidade do conhecimento para executá-lo. Entretanto, isso foi alterado com o processo de industrialização, intensificado a partir dos anos de 1930. Nessa conjuntura, 
passou-se a demandar um novo perfil de trabalhador, adaptado ao trabalho industrial e às novas relações de consumo, demandas pelo processo de industrialização.

Para a autora, a dualidade que se expressa nas relações antagônicas na sociedade brasileira também se manifesta na escola. Tendo em vista que, historicamente, a educação organiza-se de forma a corresponder aos diferentes interesses de classes, caracteriza-se como dual, pois se constitui por sistemas de ensino que possuem estruturas distintas e correspondem ao antagonismo de classes.

Ao discutir sobre a dualidade educacional, essa autora destaca que ela surge no Brasil a partir do momento em que pequena parte das classes populares passa a ter acesso à escola. O ensino secundário, nessa lógica, torna-se ponto determinante da reforma Francisco Campos, de 1931. Ao mencionarem sobre essa reforma, Shiroma, Moraes e Evangelista (2002) destacam que foi criado, pela primeira vez, um sistema nacional de educação, passando o Estado a controlá-la em todo território nacional.

Porém, foi com a reforma de Gustavo Capanema que se estabeleceu um sistema paralelo de ensino, com formação profissional para os trabalhadores. Através da implementação das leis orgânicas, como a do ensino secundário de 1942, promulgada pelo Estado Novo, o então ministro Gustavo Capanema acentuou a velha tradição do ensino secundário acadêmico, propedêutico e aristocrático. Simultaneamente a essa lei, existiam outras legislações que regulamentavam o ensino profissional nos diversos ramos da economia, bem como o ensino normal. Havia, portanto, duas estruturas educacionais, paralelas e independentes.

Essa reforma, que instituiu cursos profissionalizantes e formalizou a dualidade do ensino no país, legitimou um modelo de formação para aqueles que iriam conduzir a nação, e outro voltado para formação profissional, destinada aos que iriam impulsionar o processo de industrialização. “Consolidou-se assim a partir da Reforma Francisco Campos, a dualidade dentro do sistema público de Ensino, levada as últimas consequências na dualidade de sistemas, resultado final da gestão Capanema no que tange ao ensino técnico-profissional”. (XAVIER, 1990, p. 114).

Esse ensino paralelo, representado pelo Sistema S, foi criado pelo Estado para manter um sistema de adequação da força de trabalho à nova exigência do capital. $\mathrm{O}$ discurso que o justificou se pautava na ineficiência do Estado em prover a formação para o trabalho. Instituições sociais como o Serviço Nacional de Aprendizagem Industrial (Senai) e o Serviço Nacional de Aprendizagem Comercial (Senac) são resultantes dessa lógica. 
O Senai absorveu a formação de mão de obra especializada. Como apenas a contribuição da escola pública não era suficiente para sanar as demandas de formação de mão de obra, apresentou-se como alternativa mais adequada, constituindo o marco na história do ensino industrial brasileiro, conforme Machado (1989). Para Kuenzer (2005), o Senai e o Senac complementaram o sistema privado de formação, em um amálgama entre o público e o privado, para atender as demandas do desenvolvimento industrial, que exigia mão de obra qualificada, formada por meio de cursos específicos de formação profissional na rede pública ou privada. Para essa autora, as reformas do ministro Gustavo Capanema emergiram da incapacidade do Estado de oferecer capacitação profissional em larga escala. Diante disso, recorreu-se e se tornou possível, ao mesmo tempo, o seu oferecimento pela Confederação Nacional da Indústria (CNI).

A proposta da Reforma Capanema, em 1942, teve por objetivo atender as mudanças no mercado de trabalho. Desenvolveu-se, a partir de então, uma nova proposta pedagógica, com a oferta de educação para uma parcela elitizada da população. Nessa conjuntura, também foram criados e ofertados pelo Estado os cursos médios de segundo ciclo, com duração de três anos, na perspectiva de preparar os educandos para o ingresso no ensino superior; bem como uma escola que preparava para o trabalho.

Essa estrutura dual de ensino se justificava pela necessidade de a escola estar em consonância com o processo produtivo. Por isso, havia, de forma paralela, a educação geral e a organização do ensino profissional, industrial, agrícola, normal e comercial. Esse arranjo reforçava uma formação profissional destinada aos educandos, para ingresso no ensino superior, e outra, voltada para a formação da classe trabalhadora. Dessa maneira, consolidava-se o marco da dualidade no ensino, conforme expressa Machado (1989).

Com a promulgação da Lei $n^{\circ} 4.024 / 1961$, a LDB, os concluintes do colegial técnico puderam candidatar-se para cursos de nível superior (BRASIL, 1961). Contudo, ao mesmo tempo em que a legislação dava bases para as classes populares, advindas da formação profissional, ingressarem no curso superior, ela intensificava a necessidade da oferta de educação profissional, reforçando o discurso hegemônico que colocava a educação como necessária para atender as demandas do processo produtivo.

A partir de 1964, a formação profissional passou a assumir importante papel para o desenvolvimento industrial, atendendo, de forma mais contundente, a demanda do setor produtivo, intensificada pelo milagre econômico, de acordo com Frigotto, Ciavatta e Ramos (2004). O 
desenvolvimento econômico, com vistas a impulsionar o desenvolvimento industrial, forneceu bases para a consolidação do tecnicismo no Brasil, fortalecendo as demandas do setor produtivo sobre o Ensino Médio, que era formação de mão de obra técnica e profissional.

Kuenzer (2005) ressalta que, em decorrência das alterações no mundo do trabalho, houve o desenvolvimento de vários ramos profissionais. Devido à aceleração da demanda dos setores secundário e terciário, a LDB de 1961, pela primeira vez, integrou o ensino profissional ao sistema regular de ensino, correspondendo à continuidade do ensino iniciado no nível anterior, tendo como finalidade a formação do adolescente. Todavia, a integração do Ensino Fundamental e Médio não deu conta de romper com a dualidade da educação, mas avançou o caráter legal, que reconhecia a educação profissional como continuidade dos estudos posteriores ao Ensino Fundamental.

Para essa autora, no sentido de subsidiar essa dualidade, a Lei $\mathrm{n}^{\circ}$ 5.692/1971 (BRASIL, 1971) tornou compulsória a educação profissional e consagrou o dualismo educacional, ao propor um ajuste à nova fase de desenvolvimento, pautado na lógica do capital financeiro, demandando mão de obra de nível técnico. Pimenta (2001) compartilha dessa ideia e destaca que o ensino de segundo grau passou a ser obrigatoriamente profissionalizante. Essa obrigatoriedade, porém, não se generalizou, flexibilizando-se com a aprovação do Parecer $n^{\circ} 76 / 1975$, posteriormente revogado pela Lei $n^{\circ}$ 7.044/1982 (BRASIL, 1982).

De acordo com Kuenzer (2005), a Lei no 5.692/1971 (BRASIL, 1971) veio cumprir um duplo propósito: conter a demanda para o Ensino Superior, ampliada a partir da LDB de 1961 (BRASIL, 1961), e atender a solicitação por técnicos de ensino médio. A justificativa por tornar esse nível de ensino compulsório se sustentava-se nas críticas ao ensino geral, que não garantia o atendimento das demandas por técnicos no Brasil, tampouco atendia aos anseios dos jovens, de forma a prepará-los para o ingresso no Ensino Superior. Sendo assim, o argumento da escassez de técnicos e a frustração dos jovens que não ingressavam nas universidades, nem no mercado, por falta de habilitação profissional, foram elementos que constituíram o discurso legitimador da formação técnica.

Esse discurso instituiu a compulsoriedade, ou seja, a obrigatoriedade do ensino médio profissional. Porém, houve uma resistência por parte dos pais e alunos, bem como da estrutura educacional e empresarial, em aceitar esse modelo de formação. Esse quadro culminou na aprovação da

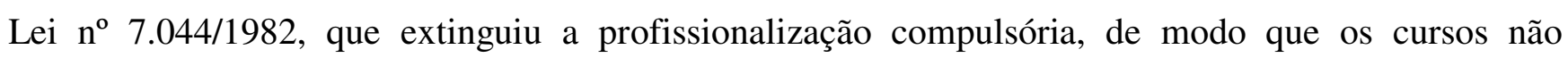
profissionalizantes deveriam incluir as 2.200 horas como carga horária destinada totalmente à formação geral (BRASIL, 1982). Essa lei recuperou o dualismo pautado em outra característica, expresso nos 
conteúdos de formação, com um sistema de educação geral, e outro, de nível técnico profissional, voltado para a formação da classe trabalhadora.

Conforme ressaltam Frigotto, Ciavatta e Ramos (2011, p. 9), “Com isto, os estudantes que cursavam o ensino técnico ficavam privados de uma formação básica plena que, por sua vez, predominava nos cursos propedêuticos, dando àqueles que cursavam esses cursos, vantagens em relação às condições de acesso ao ensino superior”.

Dessa forma, a Lei $n^{\circ}$ 7.044/1982 (BRASIL, 1982) normatizou um novo arranjo de caráter conservador, o que já vinha ocorrendo nas escolas por meio de práticas de ensino, reforçando a organicidade da concepção do Ensino Médio para ingresso no Ensino Superior. Favorecia, dessa forma, uma elite privilegiada, detentora dos benefícios da produção e consumo, como os bens materiais e culturais. Ao trabalhador, ao contrário, foi destinada uma educação fragmentada, atrelada às demandas produtivas. Para esse grupo, era necessário o domínio de técnicas repetitivas, a serem aplicadas com eficiência e prática na execução de suas funções laborais, pautadas no aprender a fazer. Reforçava-se, assim, a dualidade educacional, reflexo da histórica diferença de classes. Ao longo do processo histórico, o modelo que foi sendo ajustado tinha a exclusividade de atender as necessidades do mercado de trabalho, bem como das relações sociais em curso.

Na década de 1980 foi apresentada a primeira proposta para o Ensino Médio por educadores progressistas, através do deputado Otávio Elísio, em dezembro de 1988. Essa proposta teve como objetivo fazer com que a formação profissional não substituísse a formação básica. Este projeto foi vencido, sendo aprovado um novo, resultante de seu desdobramento.

O substitutivo Jorge Hage foi apresentado anteriormente à aprovação da LDB de 1996 (BRASIL, 1996). Saviani (1997) entende essa lei como resultado de um enxugamento de direitos que eram garantidos no texto de Hage, cuja concepção marcava uma proposta democrática socialista, amplamente compreendida como direito social garantido pelo Estado. As emendas substituíram o texto original e, segundo o autor, tratou-se de uma manobra que privilegiava os interesses dos grupos privados.

Em relação ao Ensino Médio, a formação previa maior vinculação dos níveis de estudo com a formação profissional. Essa etapa da educação pressupunha a formação politécnica, que, conforme Saviani (1997), caracteriza-se pelo domínio do trabalho manual e intelectual, ou mesmo pelo conhecimento dos fundamentos científicos das diferentes técnicas que incorporam o processo de trabalho produtivo moderno. Trata-se de um conceito desvinculado de polivalência, ao mesmo tempo 
em que recusa a formação voltada para o adestramento, ou conhecimentos limitados à execução de determinadas tarefas, conforme demandas do mundo produtivo. Porém, requer um trabalhador com conhecimento que incorpore a prática produtiva, visto que há um domínio dos fundamentos do trabalho. No resultado da reforma, a politecnia foi substituída pela polivalência, que não confere a articulação entre o conhecimento científico, teórico, tecnológico e prático.

Ao analisar a LDB de 1996 e o Substitutivo Jorge Hage, Saviani (1997, p. 213) considera que:

Essa ideia de politecnia, que havia orientado a elaboração da proposta preliminar por mim apresentada, foi se descaracterizando ao longo do processo restando dela, na Lei, apenas o inciso IV do artigo 35, que proclama como finalidade do Ensino Médio "a compreensão dos fundamentos científico-tecnológicos dos processos produtivos...", reiterado pelo Inciso I, do parágrafo primeiro do artigo 36: "domínio dos princípios científicos e tecnológicos que presidem a produção moderna".

A proposta vencedora consubstanciou-se na Lei n ${ }^{\circ}$ 9.394/1996, a LDB, com a apresentação do então senador Darcy Ribeiro (BRASIL, 1996), e, posteriormente, o Decreto $n^{\circ}$ 2.208/1997, que regulamentou a educação profissional e sua relação com o Ensino Médio (BRASIL, 1997). Como parte original do Substitutivo Jorge Harge, permaneceu apenas o art. 36 da LDB, que se refere ao ensino médio. Os demais avanços desse substitutivo foram suprimidos, o que deixou a referida Lei minimalista no que concerne aos direitos e condições para garantir a qualidade educacional nessa etapa de ensino.

O trajeto tortuoso, configurado pelas diversas forças políticas, tomou forma na LDB de 1996, conforme Frigotto, Ciavatta e Ramos (2011). Resolver a questão da dualidade no Ensino Médio por meio da proposta dos educadores referente à LDB de 1996 não era compatível com a ideologia, nem mesmo com as políticas de ajuste dos anos 1990, que foram, dessa forma, combatidas e rejeitadas. As decisões foram tomadas pelo alto, mediante medidas provisórias, decretos ou por leis conquistadas no parlamento, consolidando a troca de favores, historicamente presente no Brasil. O projeto original substituído passou por transformações adequadas aos interesses do governo, impondo sua política de ajuste pontuada na educação com manutenção da dualidade educacional.

O Ensino Médio e Profissional, no contexto da década de 1990, vinculou a adequação das forças econômicas e políticas ao novo padrão de acumulação capitalista, com implementação de reformas inovadoras que levaram em conta um padrão pautado na acumulação flexível. As reformas nessa etapa de ensino se mantiveram perfeitamente adequadas às exigências do capitalismo. 
A Lei $n^{\circ}$ 9.394/1996 inaugurou um conjunto de reformas atingindo o Ensino Médio, e, ao mesmo tempo, colocando-o como etapa final da educação básica, conforme o art. 35 (BRASIL, 1996). Além disso, implementou uma nova modalidade de educação para o trabalho, prevista no art. 42, com a formação de trabalhadores, por meio de cursos desvinculados de níveis de ensino (BRASIL, 1996). Isso, conforme Cêa (2006), demonstra a influência das transformações do mundo do trabalho sobre a LDB, tornando-a flexível.

$\mathrm{O}$ art. 42 da referida lei deixou lacunas para flexibilização na formação e deu bases para a promulgação do Decreto $n^{\circ}$ 2.208/1997, que complementou a referida lei no que se refere à organização do ensino profissional (BRASIL, 1997). Dessa forma, o art. 36 da LDB de 1996 foi negligenciado, limitando-se apenas ao ensino de caráter concomitante ou subsequente, como alternativas únicas na articulação profissional aos níveis de escolaridade, conforme menciona o próprio Decreto $\mathrm{n}^{\circ}$ 2.208/1997.

Se a LDB, no art. 35 (BRASIL, 1996), colocou o Ensino Médio como obrigatório, já garantido na Constituição Federal de 1988, as consequências dessa Lei foram sentidas na ampliação da demanda, o que acabou exigindo o aumento de recursos por parte do Estado. Contudo, essa realidade se colocava contraditória às orientações de caráter neoliberal, que teve como principal característica a redução de gastos para as políticas sociais.

Como alternativa a esse novo problema, fomentado pelo crescimento das taxas de matrículas e de gastos estatais, foi aprovada a Emenda Constitucional $n^{\circ}$ 14/1996 (BRASIL, 1996), que retirou o caráter de obrigatoriedade da oferta de Ensino Médio pelo Estado (PREDOLIM, 2011). A aprovação dessa emenda contemplou o art. 42 da Lei $n^{\circ}$ 9.394/1996, que permitiu a oferta de cursos paliativos e aligeirados, sem vinculação com níveis de ensino, sendo ofertados pela iniciativa privada. Consequentemente, houve a redução do papel do Estado na oferta de uma formação que integra a ciência, cultura e tecnologia, consubstanciando-se na simples formação para o trabalho. Entretanto, essa Lei, especificamente por meio do artigo em questão, que deu bases para a aprovação do Decreto $\mathrm{n}^{\circ}$ 2.208/1997, corroborou com a conjuntura neoliberal.

Ao instituir uma nova modalidade de educação, pode-se perceber a influência das transformações no mundo do trabalho, pautadas na flexibilização e precariedade dessas relações de trabalho sobre a LDB, já que ela também segue essa tendência ao separar o ensino e educação profissional, principalmente quando permite a oferta de cursos paliativos e aligeirados de formação específica voltados à demanda da organização do trabalho que exige cada vez mais trabalhadores adaptados ao trabalho temporário, flexível, precário e instável. (PREDOLIM, 2011, p. 146). 
O Decreto no 2.208/1997, ao separar a educação geral da educação profissional, interferiu de forma significativa na identidade do Ensino Médio (BRASIL, 1997). Potencializou-se a oferta de cursos básicos, sendo esses de caráter formativo profissional, sem qualquer vinculação com o conhecimento científico, como, por exemplo, cursos de padeiro, jardinagem, cabeleireiro, entre outros. Além de não possuírem articulação com o conhecimento científico, esses cursos não careciam de maiores investimentos e, por isso, eram oferecidos, em sua maioria, pela iniciativa privada (PEDROLIM, 2011).

À medida que o Estado foi se eximindo de oferecer ensino técnico integrado e a iniciativa privada passou a oferecer formação técnica, privilegiando a oferta de cursos básicos, o referido Decreto regulamentou a educação profissional de nível técnico, estabeleceu o caráter independente e separado do Ensino Médio, tornando a educação profissional órfã do dever do Estado. No que concerne ao financiamento, as responsabilidades estatais ficaram diluídas em parcerias, de modo que o setor privado, via Sistema S, poderia nortear a formação da classe trabalhadora, de acordo com seus interesses (CURY, 2002).

Predolim (2011), ao analisar os dados do primeiro Censo da Educação Profissional, divulgado pelo Instituto Nacional de Estudos e Pesquisa Educacionais “Anísio Teixeira” (INEP) no ano de 1999, ressaltou a hegemonia do setor privado no que concerne à oferta da educação técnica nas diferentes modalidades: básica, técnica e tecnológica. Constatou-se que 2.656 instituições de educação profissional, o que corresponde a $67,27 \%$ do total nesse período, eram privadas, conforme apresenta a Tabela 1.

Tabela 1 - Número de instituições de educação profissional por dependência administrativa

\begin{tabular}{|c|c|c|c|c|}
\hline $\begin{array}{l}\text { Dependência } \\
\text { administrativa }\end{array}$ & Total & Básico & Técnico & Tecnológico \\
\hline Total (Brasil) & 3.948 & 2.034 & 2.216 & 258 \\
\hline Federal & 150 & 103 & 120 & 30 \\
\hline Estadual & 800 & 187 & 689 & 24 \\
\hline Municipal & 342 & 199 & 152 & 6 \\
\hline Privada & 2.656 & 1.545 & 1.255 & 198 \\
\hline
\end{tabular}

Fonte: Predolim (2011, p. 153).

A autora ainda destaca que os cursos de nível básico ofertados no setor privado, supostamente, são os de menor custo. Diante disso, o Decreto $n^{\circ}$ 2.208/1997 potencializou que o Estado, progressivamente, fosse eximido de suas responsabilidades no que se refere à oferta da educação profissional. Tendo em vista que o setor público deixou, a partir desse Decreto, de oferecer, de forma 
progressiva, cursos gratuitos de educação profissional, levou a população de baixo poder aquisitivo a ter que contar com sua própria sorte, caso houvesse interesse por essa modalidade de educação. O discurso que deu base para a supressão da formação profissional pública se ampara na lógica de que os cursos eram ineficientes, não atendendo as demandas do setor produtivo. No mais, os gastos eram elevados, tornando os cursos onerosos ao Estado.

Predolim (2011) também ressalta a preponderância da iniciativa privada nas taxas de matrícula da educação profissional. Os dados do INEP demonstram o total das matrículas realizadas, incorporando o nível básico, técnico e tecnológico. Destaca-se o maior investimento da esfera privada na oferta de cursos básicos, sendo aqueles de menores exigências e estruturas, de baixo custo para serem ofertados.

Os cursos básicos, além de serem considerados baratos para a iniciativa privada, são desvinculados dos níveis de estudo e voltados para a formação de mão de obra. Nesses cursos são orientados conhecimentos básicos, necessários à execução de determinadas atividades, geralmente relacionadas ao desempenho do trabalho manual, sem exigência de maiores níveis de abstração. Os números revelam que a iniciativa privada oferece mais da metade dos cursos. Na educação básica, essa oferta é de $86,6 \%$, enquanto no nível técnico esse índice é de $43 \%$, e no tecnológico a taxa é de $61 \%$, conforme evidencia a Tabela 2.

Tabela 2 - Número de matrículas na educação profissional, por nível e dependência administrativa

\begin{tabular}{l|c|r|r|r}
\hline \multicolumn{1}{c|}{$\begin{array}{c}\text { Dependência } \\
\text { administrativa }\end{array}$} & $\begin{array}{c}\text { Total de } \\
\text { matrículas }\end{array}$ & \multicolumn{1}{c|}{ Básico } & Técnico & Tecnológico \\
\hline Total (Brasil) & 2.859 .135 & 2.045 .234 & 716.652 & 97.249 \\
Federal & 184.377 & 72.966 & 101.001 & 10.410 \\
Estadual & 413.351 & 120.999 & 265.772 & 26.580 \\
Municipal & 117.928 & 79.790 & 37.150 & 988 \\
Privada & 2.143 .479 & 1.771 .479 & 312.729 & 59.271 \\
\hline
\end{tabular}

Fonte: Predolim (2011, p. 155).

Nessa lógica, o Decreto nº 2.208/1997 regulamentou a educação profissional de nível técnico, que passou a ser oferecida de forma concomitante ou subsequente ao Ensino Médio (BRASIL, 1997). Ressalta-se que a educação profissional, quando concomitante ou subsequente, ainda possui vinculação com a escolarização, o que não acontece com a oferta de cursos básicos.

Esses cursos básicos, como cabeleireiro, jardineiro, encanador, eletricista, dentre outros, por serem profissionalizantes, não exigem qualquer vinculação com níveis de estudos. Além de serem desvinculados do conhecimento científico e paliativos, esses cursos não demandam investimentos 
maiores para serem ofertados. Dessa forma, são aligeirados e baratos para aquelas instituições que se disponibilizam oferecê-los, sobretudo a partir do Decreto $n^{\circ}$ 2.208/97, que deu ampla liberdade para o setor privado, em detrimento da oferta de Ensino Médio integrado pelo Estado (BRASIL, 1997).

Ao permitir a oferta de cursos básicos, desvinculados de qualquer escolarização, criou-se um sistema de educação profissional paralelo ao ensino de caráter regular. Houve, por assim dizer, um retrocesso em relação aos princípios da LDB de 1996, embora, como já salientado, o art. 42 tenha dado bases para a promulgação de legislações flexíveis, homologadas posteriormente (BRASIL, 1996). A legalidade do Decreto proibia a existência dos cursos de nível técnico de forma integrada, com currículos distintos.

Corroborando com Predolim (2011), Oliveira (2011) ressalta que, a partir do Decreto $\mathrm{n}^{\mathbf{o}}$ 2.208/1997, a iniciativa privada demonstrou, em todos os sentidos, uma vocação para a educação profissional de nível básico, o que pode ser confirmado tanto ao verificar a quantidade de instituições, de cursos e de matrículas, como os índices que revelam seu direcionamento para esse nível de ensino. Há uma condução da educação relacionada aos interesses do mercado, cujos desdobramentos transcendem o aspecto pedagógico. Constata-se, a partir dos dados, a hegemonia do setor privado e o receituário de reformas educacionais, que tiveram, no seu interior, a defesa de uma menor intervenção do Estado nas atividades de formação profissional.

Imbuídos de uma ideologia de formação de capital humano, para o empresariado, os trabalhadores teriam os ganhos provenientes de sua qualificação, que seriam imediatamente absorvidos por ele mesmo e pelo setor patronal. Essa era a justificativa para atribuir ao próprio trabalhador a responsabilidade por sua formação, sendo ele o seu principal financiador. A consequência imediata desse posicionamento foi o aumento da privatização da educação profissional brasileira (OLIVEIRA, 2011).

Outro fator que deve ser considerado na educação profissional é o seu caráter dualista e fragmentado. Com a implementação da formação profissional separada da educação geral, reforçou-se a dicotomia entre o pensar e o fazer, levando os setores populares a serem obrigados a procurar a iniciativa privada para conseguirem uma qualificação profissional. É preciso ressaltar que eles são discriminados pelos conteúdos ministrados nessas formações, constituídos, em sua maioria, por cursos de formação básica (OLIVEIRA, 2011).

Fica cada vez mais evidente que a possibilidade de se construir uma educação que esteja igualmente voltada aos interesses de toda população, no que se refere à qualidade ou aos objetivos 
pretendidos, somente poderá se consolidar em outro modelo de sociedade, cuja igualdade social seja seu denominador comum.

Oliveira (2003) observa, nos documentos emitidos pela Confederação Nacional da Indústria (CNI), a visão do empresariado, que articulava uma formação voltada para as demandas do processo produtivo, sustentando-se no incentivo à formação de novas competências através de instituições tradicionais, como o Sistema S.

Nele se sustentou que o incentivo à formação de novas competências por parte das instituições tradicionais (Sistema $S$ ) na educação profissional teria uma repercussão direta no aumento das possibilidades de os trabalhadores inserirem-se no mercado de trabalho, em contínua mudança (empregabilidade). (OLIVEIRA, 2003, p. 257).

Conforme o autor, o setor privado, representado pela CNI, fomentou a maior demanda de formação profissional, já que havia uma redução do Estado quanto à responsabilização de sua oferta. Assim, reforça-se o discurso que atrela a empregabilidade à formação de trabalhadores, desconsiderando as contradições geradas pelo próprio sistema, que repele e exclui trabalhadores com níveis de formação maiores.

Para Predolim (2011), se o Decreto no 2.208/1997 viabilizou a intensificação da dualidade no Ensino Médio, potencializou, ainda, a oferta de cursos aligeirados. Sob a justificativa dos reformadores de proporcionar uma formação que atendesse aos interesses produtivos, outras reformas foram necessárias a essa "nova" formação.

Cursos rápidos e aligeirados deveriam ter, consequentemente, outro rol de conteúdos, que viessem a calhar com essa nova proposta. Para a educação geral, oferecida pelo Estado, isso não foi diferente. Um conjunto de reformas em relação aos conteúdos também foram conclamadas pelos gestores estatais, inauguradas com o Parecer $n^{\circ}$ 15/1998, que delineou a implementação das Diretrizes Curriculares para o Ensino Médio, complementada, posteriormente, pelos Parâmetros Curriculares Nacionais para o Ensino Médio (BRASIL, 2000).

Nessa mesma direção o então Ministro da Educação destaca que as reformas curriculares são fundamentais para garantir a preparação para a vida. $\mathrm{O}$ mesmo define que tal preparação deve afastar a escola dos velhos métodos de disciplinas rígidas, bem como preparar o sujeito para a vida democrática, fazer da escola um espaço de socialização de crianças e jovens, visando à integração social, em detrimento de atitudes que favoreçam a discriminação e intolerância. (PREDOLIM, 2011, p.164).

Essas reformas tiveram como característica a organização de conteúdos voltados para a formação de competências e de valores. Os alunos deveriam ser formados de modo a desenvolverem 
atitudes voltadas para a tolerância e respeito às diferenças, em detrimento da secundarização dos conteúdos científicos.

Se o Ensino Médio historicamente seguiu a trilha de uma formação que reflete a dualidade de classes, atingindo a estrutura da educação, as reformas dos anos 2000, embora tenham avançado em alguns aspectos, não puseram fim a essa ocorrência. Nesse contexto, em razão dos embates e diferentes interesses de classes no interior do Estado, foi outorgado o Decreto n ${ }^{\circ}$ 5.154/2004 (BRASIL, 2004), que revogou o Decreto $n^{\circ} 2.208 / 1997$.

Ao discutir sobre a gênese do Decreto $n^{\circ}$ 5.154/2004, Frigotto, Ramos e Ciavatta (2011) recuperam as discussões que permearam a sua aprovação, bem como as controvérsias que cercearam a revogação do Decreto $n^{\text {o }}$ 2.208/1997, como o destaque para as lutas sociais dos anos 1980 pela redemocratização do país e em contraposição ao autoritarismo. O marco desse processo esteve na mobilização do Fórum Nacional em Defesa da Escola Pública, que reivindicava um sistema público e gratuito de educação, o qual deveria ser contemplado na constituinte e na nova LDB.

O novo decreto não foi desprovido de mobilização e foi perpassado por diversos interesses. Inclusive, houve três propostas anteriores, que disputavam a sua efetivação e fomentavam o debate entorno do mesmo. A primeira, ancorada na LDB de 1996, defendia a ideia de revogação do Decreto $n^{\circ}$ 2.208/1997, bem como o fortalecimento da organização do Ensino Médio. No mais, criticava a continuidade de mudanças oriundas de decretos estabelecidos pelo governo, com reprodução de método impositivo anterior. A segunda proposta defendia a manutenção do atual decreto e propunha apenas mínimas alterações. A terceira posição, por sua vez, partilhava da ideia da revogação do decreto, defendendo a promulgação de um novo. Esses documentos ofereceram sugestões de supressão, melhoria e acréscimo para o novo Decreto no 5.154/2004 (BRASIL, 2004).

A primeira e a segunda proposta trataram de interesses antagônicos. Já a terceira proposta compreendia que a simples revogação do decreto, e não garantia a implementação de uma educação pautada na formação integral do trabalhador. Para isso, eram necessárias mudanças substanciais, que deveriam ser contempladas com uma formação baseada na politecnia e nos domínios dos fundamentos do trabalho pelo trabalhador, o que não correspondia aos objetivos das forças conservadoras, que disputaram e impuseram suas relações de força nas definições dos rumos da educação de nível médio, inviabilizando a aprovação dessa proposta.

Ao discutirem sobre essa reforma, Frigotto, Ramos e Ciavatta (2011) analisam o processo contraditório de revogação do Decreto n 2.208/1997 e a construção do Decreto n ${ }^{\circ}$ 5.154/2004. Os 
autores inferem que o mesmo, embora tenha dado condições para o retorno da formação profissional integrada, não conseguiu suprimir a dualidade educacional no Ensino Médio. No embate de diferentes interesses, prevaleceu a lógica produtiva, que foi ganhando contornos e delineando a nova legislação, a partir das demandas do mercado.

No lugar de uma formação mais completa, com integração entre ciência, cultura, trabalho e tecnologia, o Decreto $n^{\circ} 5.154 / 2004$ correspondeu à hegemonia dos grupos conservadores, que clamavam pela não revogação do decreto anterior. Esses grupos conseguiram legitimar seus interesses, dada a continuidade de uma educação atrelada às demandas do processo produtivo, garantidas com a consolidação desse novo decreto.

Os autores, que participaram das discussões que deram base para a formulação do Decreto $\mathrm{n}^{\mathbf{o}}$ 5.154/2004, viam, no interior do debate e em meio às disputas, a possibilidade de retomar a integração do ensino profissional. Esse retorno não deveria limitar-se ao simples regresso de disciplinas que oferecessem educação geral, restritas à formação de competências. O que se reivindicava era uma organização que integrasse os princípios que viabilizam a formação integral, a partir da articulação entre ciência, cultura, humanismo e tecnologia.

Portanto, o ideário da politecnia buscava e busca romper com a dicotomia entre educação básica e técnica, resgatando o princípio da formação humana em sua totalidade; em termos epistemológicos e pedagógicos, esse ideário defendia um ensino que integrasse ciência e cultura, humanismo e tecnologia, visando ao desenvolvimento de todas as potencialidades humanas. Por essa perspectiva, o objetivo profissionalizante não teria fim em si mesmo nem se pautaria pelos interesses do mercado, mas constituir-se-ia numa possibilidade a mais para os estudantes na construção de seus projetos de vida, socialmente determinados, possibilitados por uma formação ampla e integral. (FRIGOTTO; RAMOS; CIAVATTA, 2011, p. 10).

Porém, esse projeto foi vencido e o resultado foi a substituição do Decreto n ${ }^{\circ}$ 2.208/1997 pelo Decreto $n^{\circ}$ 5.154/2004, vigorando, na sua essência, os mesmos interesses. Manteve-se a dualidade da educação, refletida na intensificação da formação para as demandas do mercado em detrimento da politecnia, ou da formação integral, com ênfase no desenvolvimento das potencialidades humanas e no domínio sobre os fundamentos do trabalho.

Nessa mesma perspectiva, Cêa (2006) destaca que, após a revogação do Decreto nº 2.208/1997, não houve a retomada oficial da oferta de Ensino Médio integrado à formação para o trabalho, conforme previsto na Lei $n^{\circ}$ 9.394/1996 e afirmado no atual Decreto $n^{\circ}$ 5.154/2004 (BRASIL, 2004). 
Analisando dados do INEP, a autora percebe essa insuficiência em vários estados brasileiros, com aberturas restritas de turmas nos primeiros anos após sua aprovação. Esse Decreto não conseguiu, conforme a autora, promover um retorno imediato dessa forma de escolarização nos diferentes sistemas de ensino (federal e estaduais), “[...] nem as "novas" orientações do atual decreto alteraram ou conseguiram romper com o caráter reducionista que marca, ainda hoje, a formação do trabalhador no país" (Ĉ̂EA, 2006, p. 9).

Esse movimento foi verificado em âmbito nacional, visto que os dados de matrículas mantiveram-se praticamente inalterados, mesmo havendo um decreto permitindo a abertura de novas turmas de ensino médio integrado.

Em 2004, as matrículas no Ensino Médio foram 9.169.357, contra 9.032.320 registradas em 2005, o que significa um índice de - 1,5\% de matrículas nesse nível de ensino em todo o Brasil. No caso da educação profissional de nível técnico, ao contrário, verifica-se um crescimento de 4,4\%: de 676.093 matrículas em 2004 passouse para 705.628 em 2005 (BRASIL. INEP, 2005, tabelas 4 e 8). (CÊA, 2006, p. 9).

Como enfatizado, a discussão do Decreto $n^{\circ}$ 2.208/1997 era central no sentido de viabilizar a sua superação e, em contrapartida, dar bases para construir uma nova proposta de educação profissional, consolidada pela aprovação do Decreto ${ }^{\circ}$ 5.154/2004. Os marcos desse processo estão na mobilização do Fórum Nacional em Defesa da Escola Pública, com reivindicação de um sistema público e gratuito de educação, o que deveria ser contemplado na Constituição de 1988 e na nova LDB de 1996.

Diante da leitura dos autores Frigotto, Ramos e Ciavatta (2011), um conjunto de acontecimentos foi significativo para compreender as reformas do Ensino Médio, principalmente a consolidação do

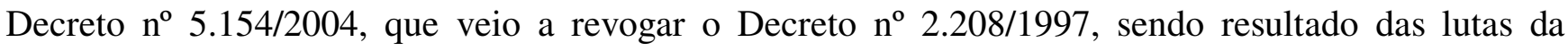
sociedade civil em defesa da educação pública de qualidade, na tentativa de propor a ampliação do Ensino Médio e combater a dualidade que, historicamente, marcou essa etapa de ensino.

No entanto, o movimento de educadores e a pressão para a promulgação de outro decreto não se consubstanciaram na superação da dualidade existente no Ensino Médio. Essa dualidade foi reforçada com o novo decreto, embora ele tenha recuperado a oferta de educação de nível médio integrado, com a articulação da educação profissional ao sistema de ensino.

O desenlace desse embate acerca dos desafios a serem enfrentados pelo Ensino Médio, enquanto etapa intermediária entre o Ensino Fundamental e a formação de nível superior, sua concretização como educação de qualidade e de uma política pública de formação geral, depende, 
sobretudo, do compromisso político, que é algo a ser construído no interior da sociedade brasileira e das relações de força em disputa. Esse quadro também aponta para a necessidade de se traçar um novo debate, voltado para romper com a lógica mercantilista da educação.

É notório que, apesar da promulgação do Decreto n ${ }^{\circ}$ 5.154/2004 apresentar limites no que se refere à sua integração, a partir de 2005, tem-se a retomada do Estado na oferta de Ensino Médio. Embora de os dados mostrarem-se ainda tímidos nos primeiros anos, como expressou CÊA (2006), houve a ampliação de matrículas nessa etapa de ensino, conforme censo escolar referente ao estado do Paraná, expresso na Tabela 3.

Tabela 3 - Número de matrículas no Ensino Médio, segundo a dependência administrativa, no estado do Paraná, conforme censo escolar

\begin{tabular}{c|r|r|r|r|r|r|r}
\hline Dependência & \multicolumn{1}{c|}{2005} & \multicolumn{1}{c|}{2006} & \multicolumn{1}{l}{2007} & \multicolumn{1}{c}{2008} & \multicolumn{1}{c}{2009} & \multicolumn{1}{l}{2010} & \multicolumn{1}{c}{2011} \\
\hline Estadual & 409.489 & 418.495 & 416.626 & 416.596 & 416.869 & 418.084 & 413.839 \\
Federal & 2.826 & 2.020 & 2.191 & 3.112 & 3.557 & 3.574 & 3.973 \\
Municipal & 44 & 0 & 0 & 0 & 0 & 0 & 0 \\
Privada & 55.849 & 60.012 & 49.217 & 51.461 & 52.377 & 55.702 & 61.092 \\
Total & 468.208 & 480.527 & 468.034 & 471.169 & 472.803 & 477.360 & 478.904 \\
\hline
\end{tabular}

Fonte: Lopes (2013, p .93).

Os dados da Tabela 3 demonstram a supremacia do setor público na oferta de Ensino Médio, no decorrer dos anos. Mas, conforme dados do ano de 2011, identificou-se que 87,25\% das matrículas são ofertadas pelo setor público, consubstanciando, assim, a ampliação da oferta do Ensino Médio nessa esfera em detrimento da oferta pela iniciativa privada, representada por apenas $12,75 \%$ das matrículas no referido ano. Esse panorama, em grande medida, é resultado do Decreto $n^{\circ}$ 5.154/2004, que retomou a supremacia do Estado na oferta de educação profissional de nível médio, invertendo a lógica que colocou, nos anos 1990, a inciativa privada como a principal protagonista dessa formação.

Nessa nova conjuntura, houve, também, a reformulação do Ensino Médio ofertado pelas instituições federais. Embora essas instituições tenham como principal foco a graduação e a pósgraduação, oferecem, concomitante, cursos de educação profissional técnica de nível médio, nas modalidades integrada e subsequente.

Ressalta-se que a Rede Federal de Educação Profissional, Científica e Tecnológica teve início em 1909, com a criação de dezenove escolas de aprendizes e artífices, as quais, na década de 1970, deram origem aos Centros Federais de Educação Profissional e Tecnológica (Cefet). Em 2008, havia 31 Cefets, 75 Unidades Descentralizadas de Ensino (UNEDS), 39 escolas agrotécnicas, sete escolas 
técnicas federais e oito escolas vinculadas às universidades, que passaram a integrar, a partir da Lei $\mathrm{n}^{\circ}$ 11.892/2008 (BRASIL, 2008), os Institutos Federais de Educação, Ciência e Tecnologia - Institutos Federais e as Universidades Tecnológicas Federais (LOPES, 2013). A construção de novas unidades federais, a partir desse período, constituiu-se como um marco nas políticas educacionais, ao passo que contribui para atender a demanda por educação profissional (LOPES, 2013).

O princípio da proposta pedagógica dos Institutos Federais é a oferta de educação básica, especialmente com cursos de ensino médio integrado; a educação profissional técnica em geral; graduação tecnológica; licenciaturas; e bacharelado, nas áreas em que a ciência e a tecnologia são determinantes. Além disso, visa a oferecer programas de pós-graduação lato e stricto sensu, assegurando a formação de caráter inicial e continuada para os sujeitos sociais (LOPES, 2013).

De 1909 a 2002, foram construídas 140 escolas técnicas no Brasil. De 2003 a 2010, houve a entrega de 214 escolas pelo Ministério da Educação (MEC), conforme previa o plano de expansão da Rede Federal de Educação Profissional, além da federalização de outras escolas em todo território nacional. Até 2012, o país contava com 354 unidades e mais de 400 mil vagas em todo país. A previsão é de ampliação de mais de 208 novas escolas para serem entregues até 2014, que somarão 562 unidades, gerando, aproximadamente, 600 mil vagas (LOPES, 2013).

Com os Institutos e Universidades Teológicas Federais, inicia-se uma nova fase da oferta de Ensino Médio Integrado, na tentativa de inovar a partir de características, experiências e necessidades próprias, fomentadas pelas demandas econômicas e produtivas de cada região. Nessa lógica, a implantação e ampliação dessas instituições têm como objetivo aumentar a oferta de cursos técnicos, principalmente de Ensino Médio Integrado, com base na integração entre ciência, tecnologia e cultura. Para tanto, leva-se em conta um contexto que reconhece as atuais políticas de educação profissional no Brasil, fortalecendo o processo de inserção de milhões de brasileiros, com multicampos especializados, nos diferentes níveis de ensino (LOPES, 2013).

Ressalta-se que os avanços na política da educação no Ensino Médio dependem do jogo de forças políticas, econômicas, sociais e culturais presentes no interior da sociedade. Isso determinará projetos de cunho universalistas ou conservadores. Mas é fato o avanço e a ampliação da oferta de Ensino Médio, a partir do Decreto $n^{\circ} 5.154 / 2004$, no que se refere à presença do Estado como seu principal garantidor.

As reformas da educação profissional não se restringiram à ampliação de vagas em Instituições Federais, ou à abertura de novos cursos de Ensino Médio integrado na rede pública estadual. Associado 
a elas, em 2011, foi instituído o Pronatec, como uma nova reforma da educação profissional. Esse programa é financiado pela União e tem como finalidade ampliar a oferta de educação profissional e tecnológica por meio de programas, projetos e ações de assistência técnica e financeira (BRASIL, 2011).

A oferta do Pronatec limita-se a um público prioritário, sendo destinado a estudantes do ensino médio da rede pública e famílias de baixa renda contempladas por programas federais de transferência de renda (BRASIL, 2011). Por se tratar de um programa novo, ainda são limitadas as pesquisas que o tomam como objeto de estudo.

Conforme implícito nos documentos e legislações, são objetivos do Pronatec a expansão, interiorização, democratização da oferta de cursos de educação profissional técnica de nível médio, presencial e a distância, e de cursos e programas de formação inicial e continuada, ou qualificação profissional (BRASIL, 2011). Além disso, visa-se o fomento e o apoio da expansão da rede física de atendimento da educação profissional e tecnológica; a contribuição para a melhoria da qualidade do Ensino Médio público, através da articulação com a educação profissional; a ampliação das oportunidades educacionais dos trabalhadores, por meio do incremento da formação e qualificação profissional; e o estímulo à difusão de recursos pedagógicos para apoiar a oferta de cursos de educação profissional e tecnológica.

Para Lima (2012), há uma mercantilização da educação profissional, reforçada com o Pronatec. Além disso, há continuidade de uma formação pautada na ideologia do capital humano, bem como na formação de competências, em que "Tal processo não se contradita com o produtivismo, mas o inclui, 'pseudocriando' o direito à educação, escondendo a formação para o mercado para, no final das contas, criar o mercado da formação" (LIMA, 2012, p. 75).

A execução do Pronatec fomenta um conjunto de ações, como a ampliação e expansão de vagas em instituições federais, redes estaduais e privadas, como Serviços Nacionais de Aprendizagem. Ao se tratar da ampliação de vagas, bem como da rede física, essa não está restrita às instituições públicas, mas prevê a destinação de financiamento público para sua execução também na iniciativa privada. Conforme indica o art. $2^{\circ}$, da Lei $n^{\circ} 12.513 / 2011$, que institui o Pronatec, há o incentivo à ampliação de vagas e à expansão da rede física de atendimento dos serviços nacionais de aprendizagem. (BRASIL, 2011). 
O Sistema S foi, conforme Lima (2012), o principal beneficiado com o Pronatec, já que o programa não restringe financiamento para o sistema público, mas pode ser amplamente destinado ao setor privado.

Ao demonstrar enorme abrangência de ações e aplicação de recursos, não faz distinção setorial (setores produtivos) ou institucional (público e privado, instituições A, B ou C) entre aquilo que tem sido o papel fundamental da rede pública federal (a educação profissional técnica) e o que tem sido o campo privilegiado da rede "privada" do sistema "S" (os cursos e programas de formação inicial e continuada ou qualificação profissional). (LIMA, 2012, p. 82).

Contudo, ainda se fazem necessárias pesquisas que evidenciem os impactos do Pronatec na formação de trabalhadores, bem como avaliem os dados atuais sobre que tipo de formação vem sendo ofertada pelo Sistema S. As críticas atuais consideram a supremacia do setor privado no que tange à oferta da educação profissional, cuja realidade não se difere do que foi a presença do sistema privado, quando da outorga do Decreto $n^{\circ}$ 2.208/1997, que retirou do Estado sua responsabilidade para com essa etapa da educação (BRASIL, 1997).

Diante do estudo realizado, pode-se inferir que, ao contrário do apresentado nos anos de 1990, principalmente na sua segunda metade, a atual conjuntura prevê um conjunto de ações que potencializam a expansão do Ensino Médio, obtendo as novas legislações. Isso ocorreu, principalmente, a partir do Decreto $\mathrm{n}^{\mathrm{o}} 5.154 / 2004$, que fortaleceu a retomada do Estado na oferta de cursos técnicos profissionalizantes vinculados aos níveis de ensino, embora isso não tenha significado o rompimento com a dualidade estrutural, bem como da supremacia dos interesses produtivos sobre a educação (BRASIL, 2004).

Para tanto, essa potencialização do ensino público se dá juntamente ao incentivo da esfera privada, sobretudo, com financiamentos públicos exclusivos. Legislações específicas tornam esses investimentos no setor privado moralmente legais, o que se justifica pela ampla necessidade de formação de mão de obra demandada pelo setor produtivo no Brasil.

\section{Considerações finais}

Os estudos sobre o Ensino Médio no Brasil indicam sua histórica dualidade educacional, marcada pela dicotomia intermediária entre a continuidade dos estudos e a formação para o trabalho. A luta por educação sempre foi uma demanda da sociedade. Porém, no contexto da sociedade capitalista 
periférica, ela é fortalecida, principalmente, com base no discurso que dá centralidade à vinculação entre educação e empregabilidade, visualizada na organização produtiva e por influência das reformas educacionais.

As reformas educacionais de nível médio, marcadas pela dualidade estrutural, com sistemas paralelos de formação profissional, foram inauguradas desde os anos 1940, período em que as massas começaram a, timidamente, acessar a escola. Essas reformas levaram o Estado a conter a demanda pelo Ensino Superior. Ao mesmo tempo, foi criado um sistema de ensino paralelo, voltado para a formação profissional, sendo destinado aos trabalhadores.

As décadas seguintes intensificaram essa dualidade de modo que, ao trabalhador, era reservada uma educação compatível com sua necessidade de vendedor da força de trabalho. Esse quadro dava hegemonia para reformas que privilegiavam a formação vinculada às demandas do sistema produtivo. Nesse contexto, inúmeros movimentos de educadores e intelectuais colocaram-se contra uma formação limitada às habilidades técnicas e competências, características históricas da formação profissional de ensino médio no Brasil. Embora os debates em torno da educação sejam, historicamente, um campo de lutas de diferentes interesses, prevaleceu a imposição e a vitória de forças conservadoras, ditando as reformas conforme seus interesses.

Isso foi evidenciado, sobretudo, a partir dos anos 1990, com a aprovação da LDB de 1996, que restringiu as possibilidades de avanço no que se refere à qualidade da educação, bem como sua organização a partir de conhecimentos que vinculam ciência, cultura, humanismo e tecnologia, visando à formação integral dos sujeitos. Além de viabilizar e reproduzir a dualidade educacional, a Lei $\mathrm{n}^{\circ}$ 9.394/1996 deu bases legais para a aprovação de legislações (BRASIL, 1996), como o Decreto $n^{\circ}$ 2.208/1997, que reforçou a hegemonia da iniciativa privada sob os rumos da educação profissional no Brasil (BRASIL, 1997), e o Decreto ${ }^{\circ}$ 5.154/2004, que representou o fortalecimento desses interesses, pautados na dualidade de classes (BRASIL, 2004).

Embora os dois decretos tenham em comum a influência das forças conservadoras, representadas pelo sistema produtivo, eles diferenciam-se em alguns aspectos, como a extinção de cursos profissionalizantes integralizados de nível médio, pelo Decreto $n^{\circ} 2.208 / 1997$, a redução do Estado na condução da educação profissional no Brasil, e a hegemonia do setor privado (BRASIL, 1997).

Já seu substituto, o Decreto no 5.154/2004 (BRASIL, 2004), embora tenha garantido o retorno da primazia do Estado sobre o direcionamento da educação profissional, com retorno da formação de 
ensino médio profissional com cursos de formação integrada, isso não significou a aproximação da supressão da dualidade educacional existente. Esse Decreto direcionou o fortalecimento da rede federal, mas continuou contemplando uma formação conforme as demandas do setor produtivo, o que revela o quanto esse setor ainda dita os rumos da educação profissional de nível médio no país.

Isso ficou evidente, sobretudo, com a Lei $\mathrm{n}^{\mathrm{o}}$ 12.513/2011, que instituiu o Pronatec (BRASIL, 2011), potencializando, também, o fortalecimento da rede federal, bem como de instituições públicas que aderiam o programa, ao mesmo tempo em que concedeu, e ainda concede, dinheiro público para a inciativa privada, representada especialmente pelo Sistema S.

Do Decreto $n^{\circ}$ 2.208/1997 ao Pronatec, evidencia-se a hegemonia do sistema privado, o que demonstra o quanto o Estado é subsumido aos interesses produtivos. Portanto, as discussões presentes neste artigo evidenciam que a educação é um campo de disputas e embates de diferentes interesses.

No que tange ao Ensino Médio, fica claro que o conteúdo das reformas identifica o grupo conservador como o vencedor histórico dessas lutas, em razão do seu direcionamento ou sua influência sobre as reformas educacionais. Por outro lado, são evidentes os limites do capitalismo e a impossibilidade de romper com a dualidade educacional. Se essa é uma característica do sistema, há uma demanda por maior engajamento da classe trabalhadora para propor mudanças que visam a uma formação integral, ainda sob a égide do capitalismo, para, quiçá, um dia avançar um modelo de sociedade sem diferenças de classes e, portanto, sem a dualidade educacional.

\section{REFERÊNCIAS}

BRASIL. Lei n ${ }^{\circ}$ 4.024, de 20 de dezembro de 1961. Fixa as Diretrizes e Bases da Educação Nacional. Diário Oficial da União, Brasília, DF, 27 dez. 1961. Disponível em: <http://www.planalto.gov.br/ccivil_03/leis/L4024.htm>. Acesso em: 15 jan. 2015.

BRASIL. Lei n ${ }^{\circ} 5.692$, de 11 de agosto de 1971. Fixa Diretrizes e Bases para o ensino de $1^{\circ}$ e $2^{\circ}$ graus, e dá outras providências. Diário Oficial da União, Brasília, DF, 12 ago. 1971. <Disponível em: http://www.planalto.gov.br/ccivil_03/leis/L5692.htm>. Acesso em: 15 jan. 2015.

BRASIL. Lei ${ }^{0} 7.044$, de 18 de outubro de 1982. Altera dispositivos da Lei ${ }^{\circ} 5.692$, de 11 de agosto de 1971, referentes a profissionalização do ensino de $2^{\circ}$ grau. Diário Oficial da União, Brasília, DF, 19 out. 1982. Disponível em: <http://www.planalto.gov.br/ccivil_03/leis/L7044.htm >. Acesso em: 15 jan. 2015. 
BRASIL. Lei n ${ }^{\circ}$ 9.394, de 20 de dezembro de 1996. Estabelece as diretrizes e bases da educação nacional. Diário Oficial da União, Brasília, DF, 23 dez. 1996a. Disponível em:

<http://www.planalto.gov.br/ccivil_03/leis/L9394.htm>. Acesso em: 15 jan. 2015.

BRASIL. Emenda Constitucional n ${ }^{\circ}$ 14, de 12 de setembro de 1996. Modifica os arts. 34, 208, 211 e 212 da Constituição Federal e dá nova redação ao art. 60 do Ato das Disposições constitucionais Transitórias. Diário Oficial da União, Brasília, DF, 13 set. 1996b. Disponível em: $<$ http://www.planalto.gov.br/ccivil_03/constituicao/emendas/emc/emc14.htm>. Acesso em: 15 jan. 2015.

BRASIL. Decreto ${ }^{\circ}{ }^{2} 2.208$, de 17 de abril de 1997. Regulamenta o $§ 2^{\circ}$ do art. 36 e os arts. 39 a 42 da Lei $\mathrm{n}^{\circ}$ 9.394, de 20 de dezembro de 1996, que estabelece as diretrizes e bases da educação nacional. Diário Oficial da União, Brasília, DF, 18 abr. 1997. Disponível em: <http://www.planalto.gov.br/ccivil_03/decreto/D2208.htm >. Acesso em: 8 jun. 2015.

BRASIL. Ministério da Educação. Parâmetros Curriculares para o Ensino Médio. Brasília, DF: MEC, 2000. Disponível em: <http://portal.mec.gov.br/seb/arquivos/pdf/blegais.pdf>. Acesso em: 8 jun. 2015.

BRASIL. Decreto $n^{0} 5.154$, de 23 de julho de 2004. Regulamenta o $§ 2^{\circ}$ do art. 36 e os arts. 39 a 41 da Lei $n^{\circ}$ 9.394, de 20 de dezembro de 1996, que estabelece as diretrizes e bases da educação nacional, e dá outras providências. Diário Oficial da União, Brasília, DF, 26 jul. 2004. Disponível em: $<$ http://www.planalto.gov.br/ccivil_03/_ato2004-2006/2004/decreto/d5154.htm >. Acesso em: 15 jun. 2015.

BRASIL. Lei no 11.892, de 29 de dezembro de 2008. Institui a Rede Federal de Educação Profissional, Científica e Tecnológica, cria os Institutos Federais de Educação, Ciência e Tecnologia, e dá outras providências. Diário Oficial da União, Brasília, DF, 30 dez. 2008. Disponível em: <http://www.planalto.gov.br/ccivil_03/_ato2007-2010/2008/lei/111892.htm>. Acesso em: 1 jun. 2015

BRASIL. Lei n ${ }^{\circ} 12.513$, de 26 de outubro de 2011. Institui o Programa Nacional de Acesso ao Ensino Técnico e Emprego (Pronatec); altera as Leis no 7.998, de 11 de janeiro de 1990, que regula o Programa do Seguro-Desemprego, o Abono Salarial e institui o Fundo de Amparo ao Trabalhador (FAT), no 8.212, de 24 de julho de 1991, que dispõe sobre a organização da Seguridade Social e institui Plano de Custeio, no 10.260, de 12 de julho de 2001, que dispõe sobre o Fundo de Financiamento ao Estudante do Ensino Superior, e no 11.129, de 30 de junho de 2005, que institui o Programa Nacional de Inclusão de Jovens (ProJovem); e dá outras providências. Diário Oficial da União, Brasília, DF, 27 out. 2011. Disponível em: <http://www.planalto.gov.br/ccivil_03/_ato20112014/2011/lei/112513.htm>. Acesso em: 1 jun. 2015

CÊA, Geórgia Sobreira dos Santos. A reforma da educação profissional e o Ensino Médio integrado: tendências e riscos. In: Reunião Anual da Associação Nacional de Pós Graduação e Pesquisa em Educação - ANPEd, Anais Caxambu, MG: ANPEd, 2006. Disponível em: <http://www.anped.org.br/sites/default/files/gt09-2565-int.pdf>. Acesso em: 26 de jun. 2012.

CUNHA, Luiz Antonio. O ensino de ofícios nos primórdios da industrialização. Brasília, DF: FLASCO, 2000. 
CURY, Carlos R. J. Políticas atuais para o Ensino Médio e a educação profissional de nível técnico: problemas e perspectivas. In: ZIBAS, Dagmar; AGUIAR, Márcia; BUENO, Maria. O Ensino Médio e a reforma da educação básica. Brasília: Plano Editora, 2002. p. 23-46.

FRIGOTTO, Gaudêncio; CIAVATTA, Maria; RAMOS, Marise. A gênese do decreto 5.154/2004 um debate no contexto controverso da democracia restrita. Revista Trabalho Necessário, Niterói, n. 3, 2005.

FRIGOTTO, Gaudêncio. CIAVATTA, Maria, RAMOS, Marise. A gênese do decreto 5.154/2004 um debate no contexto controverso da democracia restrita. Revista Trabalho Necessário. № 3, 2005. Disponível em:

<http://www.uff.br/trabalhonecessario/TN03\%20CIAVATTA,\%20M.,\%20FRIGOTTO,\%20G.,\%20R AMOS,\%20M..pdf>. Acesso em: 5 de jun. 2011.

KUENZER, Acácia Zeneida (Org.). Ensino Médio: construindo uma proposta para os que vivem do trabalho. 4. ed. São Paulo: Cortez, 2005.

LIMA, Marcelo. Perspectivas e riscos da Educação Profissional do Governo Dilma: Educação Profissional Local e antecipação ao Programa Nacional de Acesso à Escola Técnica (PRONATEC). Trabalho \& Educação, Belo Horizonte, v. 21, n. 2, p.73-91, maio/ago. 2012. Disponível em: <http://www.portal.fae.ufmg.br/seer/index.php/trabedu/article/viewFile/791/1038>. Acesso em: 1 jun. 2015.

LOPES, Christiani Bortoloto. O programa de transferência de renda bolsa família/benefício variável jovem: condicionalidade e descumprimento. 2013. 149f. Mestrado (Dissertação em Educação) Universidade Estadual do Oeste do Paraná, Cascavel, 2013.

OLIVEIRA, Ramon de. Empresariado Industrial e a educação profissional brasileira. Educação e Pesquisa, São Paulo, v. 29, n. 2, p. 249-263, jul./dez. 2003. Disponível em:

<http://www.scielo.br/readcube/epdf.php?doi=10.1590/S1517-97022003000200004\&pid=S151797022003000200004\&pdf_path=ep/v29n2/a04v29n2.pdf>. Acesso em: 5 jun. 2015.

OLIVEIRA. Ramon. A teoria do capital humano e a educação profissional brasileira. SENAC, São Paulo, 2011. Disponível em: <http://www.senac.br/informativo/bts/271/boltec271c.htm>. Acesso em: 6 jun. 2015.

PIMENTA, Selma Garrido. O pedagogo na escola pública. In: RANGEL, Mary. Supervisão pedagógica: princípios e práticas. 3. ed. São Paulo: Papirus, 2001.

PREDOLIM, Claudimara Bortoloto. A noção de desenvolvimento da CEPAL nas reformas do Ensino Médio no Brasil na década de 1990. 2011. 195f. Dissertação (Mestrado em Educação) - Universidade Estadual do Oeste do Paraná, Cascavel, 2011. Disponível em: <http://200.201.88.199/portalpos/media/File/educacao/Dissertacao\%20Claudimara.pdf>. Acesso em: 3 jun. 2015. 
SAVIANI. Demerval. A nova lei da educação: trajetória, limites e perspectivas. 3. ed. São Paulo. Autores associados, 1997.

SHIROMA, Eneida OTO; MORAES, Maria Célia Marcondes; EVANGELISTA, Olinda (Org.). Política Educacional. Rio de Janeiro: DP\&A, 2002.

XAVIER, Maria Elizabete Sampaio Prado. Capitalismo e escola no Brasil. Campinas, SP: Papirus, 1990. 


\section{High school: historical trajectory and educational duality present in the different reforms}

\begin{abstract}
The article presents a bibliographic study on educational duality of High School and its historical manifestation in the different reforms that have reached this stage of education. It highlights that the duality is configured in the existence of a dual system of education, which aims to serve the interests of the different existing classes within society. For this, we recovered various reforms from the 1940s up to the mid-2000s and established a dialogue with a number of authors, revealing the limits of those reforms and their links to the demands of the productive sector. Moreover, we highlighted the peculiar characteristics of the reforms of the 1990s, embodied in Law $\mathrm{n}^{\circ}$ 9.394/1996, the Law of Directives and Bases, which put High School as the final stage of basic education, whereas giving legal basis for the enactment of new laws that intensified educational duality, such as Decree $n^{0} 2.208 / 1997$, Decree ${ }^{0}$ 5.154/2004 and Law $\mathrm{n}^{0}$ 12.513/2011, which established the Pronatec. The disputes of different interests on education prompted the state to promulgate Decree $\mathrm{n}^{\circ} 51542004$ and to repeal Decree $n^{\circ} 2.208 / 1997$, reversing the role of the state regarding the provision of integrated vocational education at secondary level. A simple resumption of the State towards these policies did not mean the extinction of educational duality, given that it needs constant struggle imposed by workers in the State, particularly in the context of educational policies, as well as demands the very overcoming of this social model, based on class distinctions.
\end{abstract}

Keywords: High School. Public Polices in Education. Educational Reforms.

\section{Lycée: contexte historique et la dualité actuelle de l'éducation dans les différentes réformes}

\section{Résumé}

L'article présente une étude bibliographique sur la dualité éducative du Lycée et sa manifestation historique dans les différentes réformes qui ont atteint ce niveau de l'éducation. On souligne que la dualité est configurée sur l'existence d'un double système de l'éducation, qui vise à servir les intérêts des différentes classes existantes dans la société. Pour cela, diverses réformes ont récupéré des années 1940 jusqu'au milieu des années 2000 et on a établi un dialogue avec un certain nombre d'auteurs, en révélant les limites de ceux-lá et leur relation avec les exigences du secteur productif. En outre, les caractéristiques particulières des réformes des années 1990, consacrés dans la loi n 9.394/1996, la Directives et Bases Juridiques, qui a mis l'École Secondaire dans la phase finale de l'éducation de base, alors que a donné les base juridique pour l'adoption de nouvelles lois qui ont intensifié la dualité de l'éducation, comme le décret $\mathrm{n}^{\circ}$ $2.208 / 1997$, le décret $n^{\circ} 5.154 / 2004$ et la loi $n^{\circ}$ 12.513/2011, qui ont établi le Pronatec. Les conflits d'intérêts différents en matière d'éducation ont incité l'État à promulguer le décret $\mathrm{n}^{\circ} 5.154 / 2004$ et à abroger le décret $n^{\circ} 2.208 / 1997$, en inversant le rôle de l'Etat en ce qui concerne la prestation de la formation professionnelle intégrée au niveau secondaire. Une simple reprise de l'État à l'égard de ces politiques ne signifie pas l'extinction de la dualité de l'éducation, étant donné qu'elle demande une lutte constante imposée par les travailleurs de l'Etat, en particulier dans le contexte des politiques éducatives et de la demande du très surmonter ce modèle social, sur la base de distinctions de classe.

Mots-clés: Lycée. Politiques Publiques en Matière d'Éducation. Réformes Éducatives. 


\section{Christiani Bortoloto Lopes}

E-mail: christianilopes@yahoo.com.br

\section{Claudimara Cassoli Bortoloto}

E-mail: claudibortoloto@yahoo.com.br

\section{Shiderlene Vieira de Almeida}

E-mail: svalmeida@utfpr.edu.br
Enviado em: 18/11/2014

Aprovado em: 24/11/2015 